\title{
Clinical and surgical management of the cervical meningomyelocele in the neonates
}

\author{
Nail Özdemir ${ }^{1}$, Senem Alkan Özdemir², Esra Arun Özer³
}

1 Tepecik Research and Training Hospital, Deparment of Neurosurgery, İzmir, Turkey

2 Dr. Behçet Uz Children's Hospital, Department of Neonatology, İzmir, Turkey

${ }^{3}$ Celal Bayar University School of Medicine, Department of Neonatology, Manisa, Turkey

Introduction and aims: In our study, we aimed to evaluate the clinical characteristics, radiology, associated anomalies, pre and postoperative follow-up, surgical strategy, and prognosis with cervical meningomyelocele.

Methods: From 2012 to 2016, a total of 2 neonates were diagnosed as cervical meningomyelocele. The clinical symptoms, radiological features, operative approaches, preoperative care, postoperative management and prognosis were noted prospectively (Figure 1 and 2). At 18 months postnatal period the children were assessed by the Denver Development Screening Test-II for psychomotor delay.

Results: The procedure was performed on one female and one male. Mean birth weight and gestational age were 3635 gram and 39.5 weeks, respectively. The mean size in sac was $5 \times 5 \mathrm{~cm}$. There was no neurological motor deficits in our two neonates. Magnetic resonance imaging showed that neural tissue within the sac, hydrocephaly and Chiari type 2 malformation. Hemivertebrae and rotoscoliosis was present in patient 1. Syringomyelia of the thoracal region was present in patient 2 . The mean age of the neonates at the time of surgery was 4.5 days. The mean hospital stay was 33 days. The mean follow-up period for our cases was 2.5 years. There were no mortality, wound problems, cerebro-spinal fluid fistula and wound infection. There was no problems of ventriculoperitoneal shunt during the follow-up in our patients. Neurological examination and pyschomotor examination with the Denver Development Screning Test-II was normal in two cases.
Conclusions: The clinical presentations, results of surgery, prognosis, and psychomotor development of cervical meningomyelocele is better than of patients with thoracolumbar and lumbosacral locations of meningomyelocele.
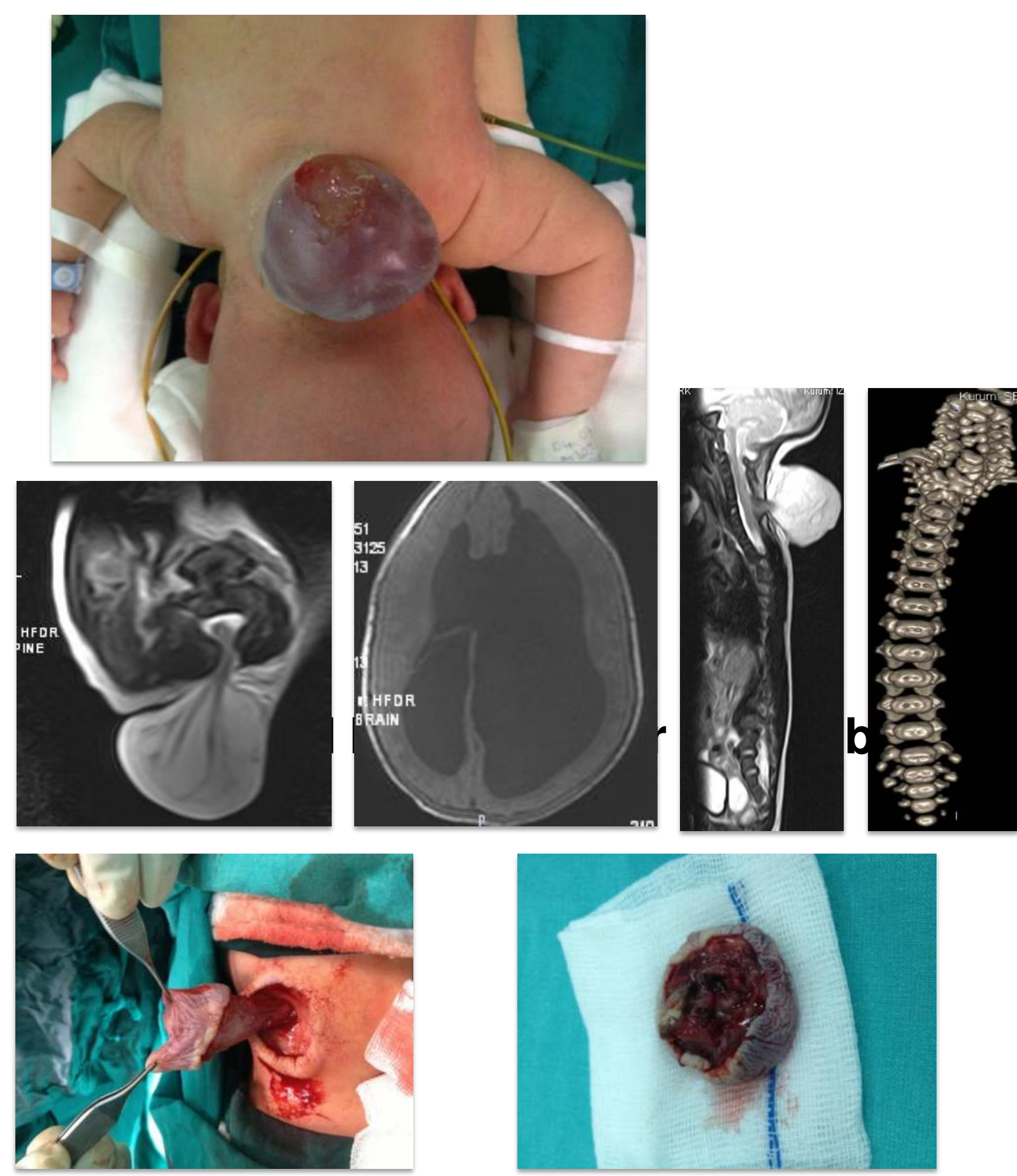

Figure 1

Figure 2
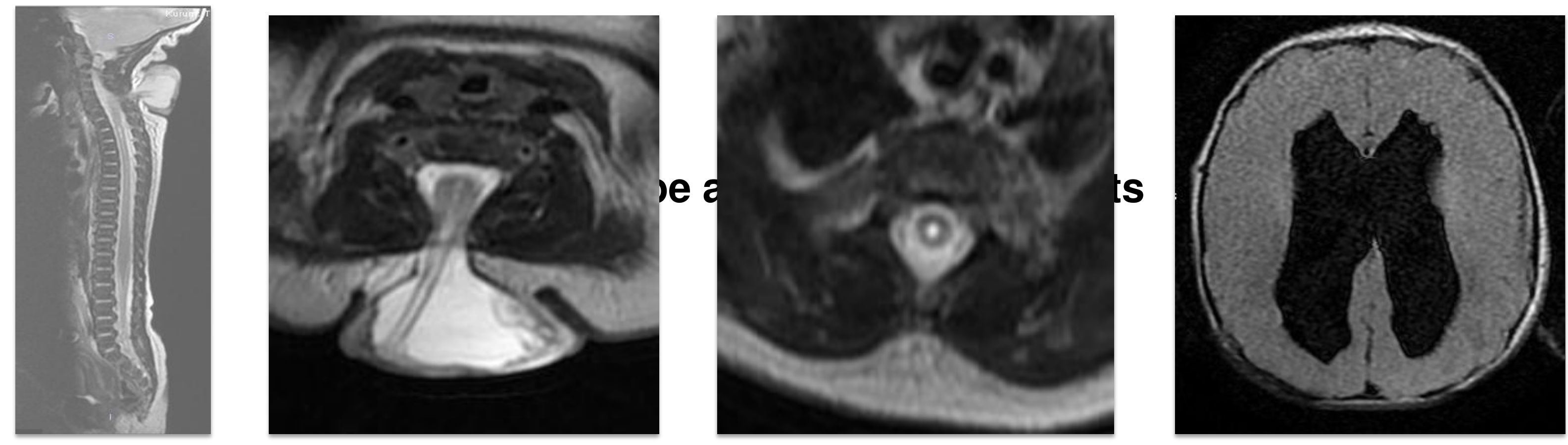